\title{
CONFLICT MANAGEMENT MODELS IN THE CONTEXT OF CONSTRUCTIVISM IN MEDIATION
}

\author{
Viktorija Portere, Baiba Briede \\ Latvia University of Life Sciences and Technologies, Latvia \\ viktorija.portere@gmail.com
}

\begin{abstract}
Mediation process promotes conflict solving, contributes to a higher level of positive solutions and decreases the number of litigation cases. The aim of the study is to outline the usage of constructive approach in mediation process, analyse conflict and its solving models and to find out the opinions of secondary school students on dialogue and conflict, as well as parties' assessments after the mediation process. The theoretical method of the study is the analysis of conflict, conflict resolution, mediation process and long-standing mediator practice. The investigation of constructivist approach, conflict elements and strategies are outlined in the study. Conflict solving models are analysed in the Methodology part of the study. Empirical methods were a structured group interview of secondary school students and questioning of conflicting parties. The results of the study confirm that knowledge on conflict and mediation should be developed at school and mediation models should be improved on the basis of constructive approach.
\end{abstract}

Key words: conflict, relationships, constructivism, mediation, skills transformation.

\section{Introduction}

Conflicting visions, assumptions, prejudices, beliefs, feelings are rooted in a variety of experiences, knowledge, awareness, and abilities. A person is a unique phenomenon who accumulates in their consciousness and subconsciousness all the information that they have gone through, learned, watched and accepted as their own. This information forms a human personality, their character, desires, interests and needs that allow having a very individual look at events, things, circumstances. The person has imagined that they need this information as a protection for their existence and growth; they can protect themselves through the accumulated experience and develop. Nevertheless, at the same time, that experience limits the person. If a person is not open enough to anything new, if they are unnecessary cautious, then the first reaction to the unknown may be negative because it does not suit them, it threatens them. This can often lead to a conflict both in social relations with others and in individual - inner conflict of the person. In such a situation, there is often a lack of knowledge and skills to help the person, easily and thoroughly explore the new circumstances or information, approbate it and analyse the consequences. It is often hindered by the emotional condition created by the feelings that have already arisen, like fear or anger. The conflict is truly resolved when all the involved parties agree that they have attained the desirable result, when no one feels a loser. When there is a loser and a winner in the conflict, the conflict can resume or move to the inner conflict of a person. After the unjust victory, there may be concerns about its fairness and the justification of the loser's suffering and feeling remorse. The losers, in turn, may plot a plan of revenge, form a coalition, or castigate themselves for the loss. This is usually the case when the victory is determined by the third party's decision. The decision of the third party is guided by the law and by the circumstances, which can be seen from their point of view, in a purely subjective manner. It leads to the necessity of developing the mediation process where a mediator helps both sides to come to the solution and exclude the necessity for legal proceedings.

Mediation is an alternative way of dealing with conflict, which is used in many countries. G. Amoh has defined the mediation process as follows: 'Mediation simply refers to the process of resolving conflict in which a third neutral party (mediator), assists the disputants to resolve their own conflict. The process is voluntary, and the mediator does not participate in the outcome of the mediation process (agreement). The disputing parties themselves have control over the agreements to be reached' (Amoh, 2007). G. Amoh concisely named four mediator skills: "1)The mediator acts to build, maintain, and improve communication between the disputants, 2) The mediator facilitates information to and between the disputants, 3)The mediator must 'befriend' the disputants in the mediation process to enhance trust and confidence, 4) To encourage what he refers to as 'active mediation'. By active mediation Curle refers to the ability to cultivate a willingness to engage in cooperative negotiation' (Amoh, 2007).

In Latvia the mediation process has officially begun since May 2014, when Mediation Law (2014) came into force.

Until now, certain areas have been studied, such as conflict, constructiveness as a model for acquiring and accumulating knowledge, constructivism in international and social relations, the mediation process and its forms. The contribution of this study is to demonstrate how the constructivism theory and 
constructive approach work in the mediation process for conflict resolution, what methods are used in the mediation process to find out the nature of the conflict, and what results can be achieved if, during mediation, the parties acquire additional abilities and skills in partnership with a professional mediator, how the mediator performs the role of the teacher while simultaneously managing the mediation process and teaching the disputants the skills that can further help them to deal with the conflicts themselves. That is why the aim of the study is to outline the usage of constructive approach in mediation process, analyse conflict and its solving models and to find out the opinions of secondary school students on dialogue and conflict, as well as parties' assessments after the mediation process.

\section{Materials and Methods}

The methods of the study were the theoretical analysis of conflict, conflict resolution, mediation process and long-standing mediator practice. The empirical methods were group interview and questioning the parties on the mediation process and conflict.

The first one was an oral survey conducted among the students of forms nine, ten and eleven (137 respondents in total), 2/3 girls and 1/3 boys from secondary schools in Latvian towns Ogre, Ikskile and Salaspils, with an aim to identifying the skills they have acquired for conflict resolution and dialogue. The study was carried out in November 2018. The results of the oral survey are presented in Table 1 .

The second empirical study covered the investigation of three mediation cases (three pairs of conflicting parties). The study was carried out in January - March 2019. Conflicting parties were questioned before and after the mediation, in the phase when they had arrived at a complete or partial conflict solution, to clarify their first opinions and feelings. The second objective was to find out what dialogue skills disputants have obtained during mediation that helped to assess the situation and recognise the other party's views. The assessment was in the gradation from one to three (one - weak; two - average; three - strong). They also ticked what dialogue skills they have obtained in the process of mediation.

The first case was family relations mediation and it lasted for eight sessions, 12 hours in total (1.5 hours each), in the model of facilitative mediation. The objective was to solve the problem of family communication. The mediator promoted the usage of eye contact, listening and hearing, emphatic listening, asking open and circular questions, rephrasing, summarising, verbalising, confronting, identifying non-verbal communication, dropping, blocking, recognising and naming emotions.
The second case also was family relations mediation during the divorcing process, and it lasted for five sessions, 7.5 hours in total (1.5 hours each), in the model of mediation for finding solutions. The parties tried to come to a solution regarding the fathers' further relations with children and the amount of maintenance. The parties considered all mediation phases. The mediator promoted the usage of eye contact, listening and hearing, emphatic listening, asking open, circular and hypothetic questions, rephrasing, summarising, verbalising, confronting, identifying non-verbal communication, dropping and blocking.

The third case was a work conflict mediation and it lasted only for one session (1.5 hours). The disputing parties tried to find a solution in the case when one person had taken material values of the employer. The mediator used the dialogue technique with the purpose to assess the situation, its causes and consequences. The disputing parties appreciated the skills of the mediator because the problem was resolved in a short period of time.

\section{Results and Discussion}

Conflict as a clash of different opinions and efforts of its solving is the main cause of introduction of mediation.

The conflict is based on two needs. The first is to protect oneself and the second - to be correct, to fit in. A person has a dual nature - he/she wants to be special with their own special beliefs, interests and needs and at the same time, they want to be a part of a family or a group. If it leads to a conflict situation, people usually want to remain accepted by the group as equals. This phenomenon 'is generally known today as a relational account of human nature and society, recognizing this dual consciousness, of simultaneous separateness and connection, as inherent in human beings' (Bush \& Folger, 2005).

It is essential for a person to find the solution to a conflict because 'of this dual quality of human nature' (Bush \& Folger, 2005).

\section{Conflict elements}

A mediation process is promoted considering the following conflict elements: degrees of conflict escalation and behavioural strategies.

A mediator has to know the degree of conflict escalation to join in more effectively. F Glasl's (2009) nine degrees are used in mediation. They are as follows: tension, debate and polemic, actions instead of words, coalitions, loss of moral credibility/complete loss of trust, threat strategies, limited destructions, fragmentation of the enemy, and together into the abyss.

Thomas-Kilmann conflict mode instrument is widely used in conflict solving practice to overcome escalation. It includes five strategies: avoiding, 
competing, accommodating, collaborating and compromising. The strategies show an individual's behaviour choice during the conflict 'along two basic dimensions: (1) assertiveness, the extent to which the individual attempts to satisfy his or her own concerns, and (2) cooperativeness, the extent to which the individual attempts to satisfy the other person's concerns' (Thomas \& Kilmann, 2010).

When the conflict turns towards understanding, 'parties can recapture their sense of competence and connection, reverse the negative conflict cycle, reestablish a constructive (or at least neutral) interaction, and move forward on a positive footing' (Bush \& Folger, 2005).

A. M. Gordon and S. Chen, following an in-depth study, have pointed out that conflict can be destructive, but by acquiring additional skills, it can be transformed into constructive and transforming relationships: 'From a conflict management perspective, conflicts are indeed thought of as damaging and destructive, but only when they are characterized by negative behaviours such as aggression, hostility, or withdrawal. When they involve positive behaviours such as affection, affiliative humour, or effective problem-solving, conflicts can instead be constructive. In line with this perspective, research shows that teaching premarital couples how to manage conflict constructively can minimize distress in the relationships' (Gordon \& Chen, 2016).

The most effective way to resolve conflicts is to analyse the circumstances of the situation, the views of the partners, the emotions, the meaning of the words used. Parties involved in the conflict must be objective in evaluating the details of the conflict, which usually is not possible because of the emotions, ambition and personalities of the parties involved. In addition, the parties of the conflict can simply lack knowledge and skills for understanding and resolving the conflict situation. In such cases, it is advisable to assess the conflict situation with the presence of a mediator, in a mediation process. The participation of a skilled mediator can highlight the true circumstances of the conflict and contribute to its resolution.

Mediation is a method of conflict resolution in which the mediator organizes the conversation in such a way that the feelings, interests and needs of each party are heard, the circumstances of the situation and future prospects, as well as the consequences of the solutions are assessed. The mediator is a specifically trained expert, who remains objective and neutral in the conflict settlement process, while emphatically understanding both parties, knows the boundaries of the legal conflict and has sufficient experience in resolving disputes and a broad view of life to help the conflicting parties to assess the causes and consequences of the conflict in question. The mediator is a skilled dialogue maker and leader. The mediator in the conflict is not only a mediator, a magistrate or a moderator, but also a teacher who, by his example and explanations, can teach the conflicting parties. Usually, if the parties do not cope with the resolution of the conflict, they are vitally affected and, therefore, the parties are motivated to find solutions to a specific conflict and also to acquire knowledge, skills and experience for future cases. That is why the mediator's role is to help and demonstrate appropriate humanistic approach in looking for solutions. Nowadays theory and practice recognise a constructivism approach because it allows to implement all the elements and functions of dialogue fostering humanistic and optimal way of conflict solution.

\section{Constructive approach in a mediation process}

Constructive approach promotes a situation when people actively construct their ideas and interpret them, and the dialogue is the main means of how to get to conclusions and results. N. Onuf(1998) stresses that 'Constructivism is a way of studying social relations - any kind of social relation'.

In mediation, with the support and knowledge of the mediator, the parties acquire a new view of themselves, the partner, and the situation, which makes it possible to see the options for solution of the conflict and to choose the best for both parties, the most suitable for an existing situation in life. As a result, both parties have won and perfected their personality, abilities and skills. Mediation is an active process in which both the mediator and the parties are actively involved, and this is the only way, in which conflict resolution may be found. Neutrality is the basic principle of the mediator, but the basic rule of the parties is self-determination. The mediator is not entitled to decide how the parties should deal with the conflict, the parties themselves have come to a solution that they consider acceptable in this situation and with which they can live. The mediation process is essentially a workout and practice that tries to identify common interests and achieve mutually beneficial results. Thus, it is practical work, practicing, in which new skills are acquired, which the parties of the conflict have lacked, to avoid escalation of the conflict. 'Practices are competent performances. More precisely, practices are socially meaningful patterns of action, which, in being performed more or less competently, simultaneously embody, act out, and possibly reify background knowledge and discourse in and on the material world' (Adler \& Pouliot, 2011).

Of course, we can say that people come into conflict because of their nature. The human character comes from experiences that are not determined by the person himself or herself and cannot be controlled. The experience just comes from life situations. You can search someone's fault for being in conflict 
or search for the cause of the conflict situation. If you question whether it is correct to analyse your behaviour and qualities when you are involved in a conflict - the answer is yes, it is important. However, if the question is, what is more important - to analyse your behaviour or to acquire skills for constructive behaviour, learning new successful skills is definitely the right answer.

When relationship of persons come to an impasse with arguments and conflicts arise, this means that the parties lack the knowledge, understanding of vision, existing in their experience and skills, and they fixate on it. Constructive approach pays attention to the widest range of social phenomena as learning peculiarities, psychology, interpersonal relations, traditions and everyday life habits. Constructivism is a learning approach traditionally but due to its humanistic ideas including support of dialogical relations it is prospective in the mediator's work. Constructivism is the adoption and approbation of other experience; it is opening oneself for something unknown.

In the mediation process the following constructivism principles are recommended: learning with meaning, finding of learning by a person himself/ herself, finding coherences and understanding entity of phenomena, active involvement in acquiring knowledge (instead of passive receiving of knowledge), active usage of contexts and the person's experience in acquiring knowledge, active involvement in selfevaluation of one's knowledge and behaviours and preserving positive atmosphere.

Usage of constructive approach in a mediation process reflects two dimensions. The first is promotion of dialogues between two conflicting parties. The second is the learning dimension when a mediator understands, controls and fosters clients' learning and transformations through dialogue.

Research of the constructive approach is still ongoing. T. Alexeyeva (Алексеева, 2014) points out 'that modern constructivists believe that in the past researchers have not assessed the effect of linguistics on relationships, and that insufficient attention has been paid to behaviour of habit and, in general, to expanding, non-reflexive behaviour'.

A person's individual system consists of needs, expectations, values, cognitive intelligence, temperament, emotional intelligence, and world view. When a person with his/her individual system meets the individual system of the other person and they start to contradict, a conflict arises. In general, the conflict is maintained if the parties cannot define and express their real interests and needs, are unable to look into the consequences of the change.

A mediator reveals the true interests and needs of the conflicting parties, helps to discuss the needs, fears, and expectations of the parties. The mediator can help to assess the actual situation and conditions more objectively, to discuss the consequences of the best solution to the situation and the consequences of the worst solution.

Using the negotiating technique, a mediator tries to get a new view of the parties to a situation where personalities are separated from the problematic situation. The mediator attracts the parties' attention to the interests and needs of the parties, but not to positions. The mediator motivates the parties to develop options that resolve the conflict situation. This usually takes place in four phases of the mediation process: clarifying the problem arising from the positions of the parties and their arguments; clarifying the facts, circumstances, interests, and needs; clarifying the desired outcome and finding possible solutions.

Mediators-practitioners A. Trosens, R. Hofmans, D.B. Rotfishere (2007) in the book 'Mediation. Fundaments of mediation in theory and practice' list and describe the most commonly used techniques, which the parties, involved in the conflict, learn by participating: active listening, reading, copying, accepting the body language, communication at metacommunication level, asking open questions, asking circular questions, encouraging, doubling, restraining, anchoring, focusing, confronting, gathering, paraphrasing, empathic listening (repeating content, paraphrasing, reflecting and naming feelings), blocking, chunking, normalizing, rephraming, mirroring, building a triad bridge, transforming, not listening, translating, verbalising, clarifying, presuming, paradoxical intervention, changing the perspective, positive rewording, distinguishing individuals and objects, modelling the situation, moderation, expanding the room for negotiation and solutions, management of brain storming.

Dialogue techniques are used in the mediation models.

\section{Mediation models}

In each of the phases, the mediator carries out successive statement activities in order to achieve the necessary mediation result. The necessary mediation result is determined by the disputant. It should be noted that conflict resolution is not always the most important and demanding destination of the mediation process that the parties want and carry out with the mediator. The mediator's services can just be used to come out of the impasse which the parties are not able to accomplish on their own. There may be a conflict between the disputants at the applied level, where parties cannot find common visions at the level of cases and activities, at the level of interests and needs, and at the level of values. Various processual models emerge from the entity of statements and activities: evaluative, transformative and facilitative mediation (Zumeta, 2018), understanding-based mediation 
(Friedman \& Himmelstein, 2006), narrative mediation (Hansen, 2003), mediation of finding solutions and e-mediation (Shonk, 2018).

Facilitative mediation. In this model of mediation a professional mediator facilitates negotiations between conflicting parties by applying the broadest spectrum of methods and techniques of dialogue: 'asks questions; validates and normalizes parties' points of view; searches for interests behind the positions taken by the parties; and assists the parties in finding and analysing options for resolution' (Zumeta, 2018), so that the parties can explore the deepest interests and needs, fears and assumptions, causes and consequences of events, the best solutions and the worst consequences if the conflict is not resolved. The model covers all phases of mediation in depth and comprehensively:

- familiarising with the nature of the mediation process and the agreements of its arrangements, rules and boundaries;

- the parties expose their vision on a situation and express their positions and the best possible conflict solutions;

- a mediator together with the disputing parties assesses the circumstances, causes and consequences of the situation;

- true emotions, feelings, interests, needs, rights and intentions of each party touched or not respected are assessed and solution options proposed;

- each party's life and cultural values and their compatibility for coexistence are clarified;

- defining of the most appropriate solution and describing its implementation process, determining each party's rights and duties, activities and terms.

A mediator keeps neutrality during the whole mediation process and parties keep self-determination. The mediator explains the nature of dialogue, necessity of its usage and consequences, and how to use the dialogue in a particular case with the purpose to find the solution.

Transformative mediation. The disputants make a dialogue, and the choice of themes and organisation of the dialogue are left to themselves. A mediator supports them and helps them to discuss the theme completely. The emphasis is placed on cognition of personalities and mutual understanding, respecting views, interests and needs, as well as gaining selfrespect and improving mutual relations. 'The potential for transformative mediation is that any or all parties or their relationships may be transformed during the mediation' (Zumeta, 2018). Conflict solving lies in the background. Deeper knowledge about the other conflicting side is at the centre of this model. The main dialogue skills are asking questions, listening and empathy. Improvement of these skills highlights understanding of each person.

Narrative mediation. This model is based on the concept that every person has his or her own story of how to get to the vison/perspective of the situation, and what is the basis of conflict solution ideas. Exchange of experience is in the centre of the model because parties share their narrations and 'build on the storytelling metaphor' (Hansen, 2003), therefore it is a way how to find out new ways for conflict solution. The phases of mediation are identified but it is not necessary to consider them strictly. Usage of versatile dialogue techniques is important in the model because they serve as the main tool of giving and receiving information.

Understanding-based mediation. Conflict solving by understanding the situation is in the centre of the model and 'the deeper understanding by the parties of their own and each other's perspectives, priorities, and concerns enables them to work through their conflict together' (Friedman \& Himmelstein, 2006). The mediator gets involved actively by using dialogue techniques and it helps both parties to understand better their own interests, priorities and prospects, and provides an opportunity to solve the conflict together. The parties are responsible for their decisions. This model is based on the assumption that both parties understand the situation and the nature of conflict and they can better decide on a solution than the mediator. The role of the mediator is to help highlight the unknown in the situation which both parties were not able to comprehend by themselves.

Evaluative mediation. The mediator manages the mediation process and takes a neutral position in assessing the situation. The mediator substantiates his or her own activities and opinions, and thus the conflicting parties learn to look at the situation from metaposition, disregarding their emotions and former experience, 'in reaching resolution by pointing out the weaknesses of their cases' (Zumeta, 2018). Dialogue techniques are used quite minimally in this model. They are used only to highlight real conditions of the case.

Mediation of finding solutions. The emphasis is placed on finding the solution in this model. Needs, interests, positions, persons, conditions of the situation are assessed as far it is necessary to come to the solution and no more. Finding mutually advantageous conflict solution as soon as possible determines the way of dialogue management and the choice of dialogue techniques. The phases of mediation under the guidance of the mediator are considered only with the purpose of finding the solution. There is an economy of time and energy. However, the effectiveness of keeping good relations between the disputants and solution could be the lowest one. 
Secondary school student statements on dialogue and conflict

\begin{tabular}{|l|c|c|c|c|}
\hline \multicolumn{1}{|c|}{ Statement } & Agree & Disagree & $\begin{array}{c}\text { Rather agree } \\
\text { than disagree }\end{array}$ & $\begin{array}{c}\text { Rather disagree } \\
\text { than agree }\end{array}$ \\
\hline I have an understanding of dialogue & 20 & 7 & 73 & 0 \\
\hline $\begin{array}{l}\text { I have enough knowledge about dialogue to solve } \\
\text { conflict at school or at home }\end{array}$ & 15 & 15 & 12 & 58 \\
\hline I have enough knowledge about dialogue to teach others & 0 & 0 & 36 & 64 \\
\hline Teachers and students use dialogue & 0 & 27 & 36 & 37 \\
\hline $\begin{array}{l}\text { I would like to get to know more about elements of } \\
\text { dialogue and how to make it }\end{array}$ & 100 & 0 & 0 & 0 \\
\hline $\begin{array}{l}\text { There is enough information in school programme to } \\
\text { foster students' understanding of dialogue }\end{array}$ & 0 & 0 & 0 & 100 \\
\hline
\end{tabular}

\section{The first empirical study}

When compiling the results, it appears that students have not obtained sufficient understanding of the nature of the dialogue and are unable to distinguish it among other forms of communication. Students have not acquired skills to deal with conflicts sufficiently. The answers showed that it is necessary to learn about dialogue and conflict at school to improve their mutual relationships. Respondents agree that they have an understanding of dialogue - $20 \%$ agree fully and $73 \%$ agree partly (Table 1). At the same time, $100 \%$ of the students recognise that there is not enough information in the school programme to foster their understanding of dialogue. They (100\%) also would like to get to know more about the elements of dialogue and how to make it, and $58 \%$ of the respondents recognise that in general they do not have enough knowledge about dialogue to solve conflicts at school or at home. Nobody agrees fully that there is a real usage of dialogue either by teachers or students and only $36 \%$ rather agree that teachers and students use the dialogue.

The results show the necessity for promotion of dialogue in everyday life, and schools have to foster learning of dialogue, understanding its role in democracy and maintaining a positive social environment.

\section{The second empirical study}

In the first case, the mediator observed that disputing parties use offered dialogue skills and they helped to come to a positive solution. The parties appreciated the new dialogue skills.

In the second and third cases, the mediator observed that disputants tried to practise dialogue techniques which allowed them to come to a solution in a quite brief period of time. They recognised that they were not able to agree without the help of the mediator because of emotional tensions and they did not use dialogue techniques.

In all three cases, when compiling the results, it can be seen that before the mediation process nearly $80 \%$ experienced insecurity and confusion, while $60 \%$ had a sense of fear and anger. On the other hand, the creators of the mediation process have changed and there was a sense of peace and security in $90 \%$ of cases.

And also in all three cases the picture was the same - among the important skills acquired during mediation, which the parties did not know before, the ability to recognise the non-verbal language of the speaker was mentioned, to predict the consequences of his/her words, to express views without imposing, to ask for other people's support and assistance, to seek common interests, to speak about emotions and to recognize them, to speak and accept the feelings and opinions of others, without fear of accepting the views and vision of the situation of others.

The mediator managed to improve communication of the parties because they acquired and practised dialogue techniques successfully.

As can be seen from the study, conflict situations frequently escalated if the parties did not possess the skills and knowledge simultaneously with emotions of how to ask questions to identify their and partner's real needs and interests, of how to analyse the consequences of conflict situations and solutions that need to be directly addressed in the event of a conflict. Once you go through the conflict with a specialist who has these skills, you gain these skills and experience. This person will definitely use this experience, skills and knowledge in future conflict situations.

Views on the development of mediation

B. Hommel analysing the need for knowledge, both in the experience and operation has indicated that 'there are reasons to assume that the main function of consciousness in action control is actually for communication with both others and oneself. Having conscious insight into aspects of action control allows us to verbalise what we are doing, how we are doing, and why we are doing it, which provides the opportunity to share tasks and strategies how to implement and control a task with others, and to use this information for self-control' (Hommel, 2017). 
Several forms of mediation are distinguished and, often, several types may be applied sequentially within the framework of a single mediation or change in the timing of the mediation process. This depends on the purpose of the participants in the mediation process. The mediator guides the parties involved in the conflict: their wishes, their capabilities and their possibilities to deal with the current conflict situation.

A mediator may operate in the mediation process, ranging from the simple negotiating moderator, who only moderates the information of the conversation, to the facilitator, who forms the negotiating area and facilitates the dialogue and transformation of the parties with a view. 'The facilitator's job is to support everyone to do their best thinking. To do this, the facilitator encourages full participation, promotes mutual understanding and cultivates shared responsibility. By supporting everyone to do their best thinking, a facilitator enables group members to search for inclusive solutions and build sustainable agreements' (Kaner et al., 2014).

In all these mediation processes, the conflicting parties participating in the settlement of the conflict with the help of the mediator are looking at new possibilities for the resolution of the conflict, acquire specific dialogue methods and practise them during the mediation process. The mediator works as a real teacher and model, and thus the parties can supplement and expand their conflict-solving skills.

\section{Conclusions}

Constructive approach is a philosophical and pedagogical basis of mediation process and determines a mediator's behaviour in conflict phases. It means that the mediator fosters relations between both conflict solving and learning of dialogue.
The usage of the principles of constructivism with the focus on the dialogue method reveals versatile opportunities for parties: learning with meaning, finding of learning by a person himself/herself, finding coherences and understanding entity of phenomena, active involvement in acquiring knowledge (instead of passive knowledge receiving), active usage of contexts and the person's experience in acquiring knowledge, active involvement in self-evaluation of one's knowledge and behaviour, and preserving positive atmosphere; looking at a situation from various angles, improving communication skills and solving a conflict.

Mediation models is a tool how to structure and manage the mediation process. To make the mediation process more successful, it is necessary to improve the models by highlighting their structure and process basing on constructivism approach and conflict theory in further research.

The choice of the model depends on the nature of conflict, time limit, dialogue scope and depth for getting solution. Disputants usually choose the model considering also the mediator's experience and view on the situation. Dialogue techniques are a relevant part of each model and, in spite of the length of the mediation process, they help to improve communication, diminish conflict and find the solution.

Dialogue skills belong to soft skills because they fit into the frame of co-operation, problem solving and decision taking. As the secondary school students think that information about dialogue skills is not included at all in their school subjects, it has to be one of the objectives in the competence-based education programmes with the purpose to explain the importance and application of soft skills. Dialogue training practice should be included in the secondary school interdisciplinary subject modules.

\section{References}

1. Adler, E., \& Pouliot, V. (2011). International practices. International Theory, 3 (1), 1-36. DOI: 10.1017/ S175297191000031X.

2. Amoh, G. (2007). Mediation - the preferred alternative for conflict resolution. Retrieved December 15, 2018, from http://www.gdrc.org/u-gov/conflict-amoh.html.

3. Bush, R.A.B., \& Folger, P.J. (2005). The promise of mediation. The transformative approach to conflict. San Fancisco, USA: Josey-Bass.

4. Friedman, G., \& Himmelstein, J. (2006). Resolving Conflict Together: The Understanding-Based Model of Mediation, Journal of Dispute Resolution 2(8).

5. Glasl, F. (2009). Konfliktmanagement: Ein Handbuch für Führungskräfte, Beraterinnen und Berater (Conflict management: a guide for managers and consultants). Bern, Switzerland: Haupt. (in German)

6. Gordon, A.M., \& Chen, S. (2016). Do you get where I'm coming from?: perceived understanding buffers against the negative impact of conflict on relationship satisfaction. Journal of Personality and Social Psychology, Vol. 110(2), 239-260.

7. Hansen, T. (2003). The narrative approach to mediation. Retrieved February 13, 2019, from https://www. mediate.com/articles/hansenT.cfm.

8. Hommel, B. (2017). Consciousness and action control. The Wiley Handbook of Cognitive Control, First Edition. Edited by Tobias Egner. Published 2017 by John Wiley \& Sons Ltd, 111-123. 
9. Kaner, S., Lind, L., Toldi, C., Fisk, S., \& Berger, D. (2014). Facilitator's guide to participatory decisionmaking (3rd ed.). San Fancisco, USA: Josey-Bass.

10. Mediation Law. (2014). Retrieved February 13, 2019, from https://likumi.lv/ta/en/id/266615-mediationlaw.

11. Onuf, N. (1998). Constructivism: a user's manual of international relations in a constructed world. In M.E. Sharpe (Ed.), International relations in a constructed world (pp. 58-78). Armonk, New York, London: M.E. Sharpe.

12. Shonk, K. (2018). Types of mediation: choose the type best suited to your conflict. Retrieved February 13, 2019, from https:/www.pon.harvard.edu/daily/mediation/types-mediation-choose-type-best-suitedconflict/.

13. Thomas, K.W., \& Kilmann, R.H. (2010). Conflict mode instrument. Profile and interpretative report. Retrieved March 7, 2019, from https://www.skillsone.com/Pdfs/smp248248.pdf.

14. Trosens, A., Hofmans, R., \& Rotfišere, D.R. (2007). Mediācija. Mediācijas pamati teorijā un praksē (Mediation. Basis of mediation in theory and practice). Riga, Latvia: Tiesu namu agentura. (in Latvian)

15. Zumeta, Z. (2018). Styles of mediation: facilitative, evaluative, and transformative mediation. Retrieved February 13, 2019, from https://www.mediate.com/articles/zumeta.cfm\#bio.

16. Алексеева, Т.А. (2014). Мыслить констуктивистки: открывая многоголосый мир (Thinking a design: discovering the many-voice world). Сравнительная политика 1 (14)/2014, 4-21. (in Russian) 